\title{
BITTER PILLS
}

\section{Counterfeit drugs are estimated to represent 10\% of the global market in medicines, rising to almost a third in some parts of the developing world. Andrew Jack reports on bids to tackle a growing threat to patients' health}

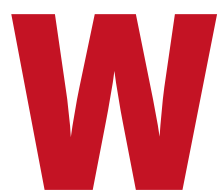
hen the UK medi-
cines watchdog
unveiled its first ever
strategy to tackle
counterfeiting last week, ${ }^{1}$ it was responding to growing concern about the increasingly complex, dangerous, and expanding international traffic in fake drugs. A few weeks earlier, the Medicines and Healthcare Products Regulatory Agency had brought to trial one of the most ambitious prosecutions to date, leading to the imprisonment of four men for handling $£ 1.5 \mathrm{~m}(€ 2 \mathrm{~m} ; \$ 3 \mathrm{~m})$ in counterfeits. ${ }^{2}$ Other cases concerning still more elaborate schemes are scheduled in the months ahead.

In the past three years, the agency has issued nine withdrawal notices for suspect prescription medicines discovered in the legal distribution chain, compared with just one in the previous decade. Pharmaceutical companies such as Pfizer have been forced into costly withdrawals of batches of their medicines faked by criminals. ${ }^{3}$

\section{Growing problem}

These incidents are almost certainly an underestimate of the extent of the traffic in counterfeit drugs in the United Kingdom. Although the agency conducts spot checks, it has limited resources to tackle a problem that has been acknowledged only relatively recently.

One indicator is European Union customs statistics, which showed a fourfold increase last year with 497 border seizures of 2.7 million medicines. ${ }^{4}$ Although lifestyle drugs such as Viagra dominated, the hauls also included significant numbers of drugs to treat hypercholesterolaemia, osteoporosis,

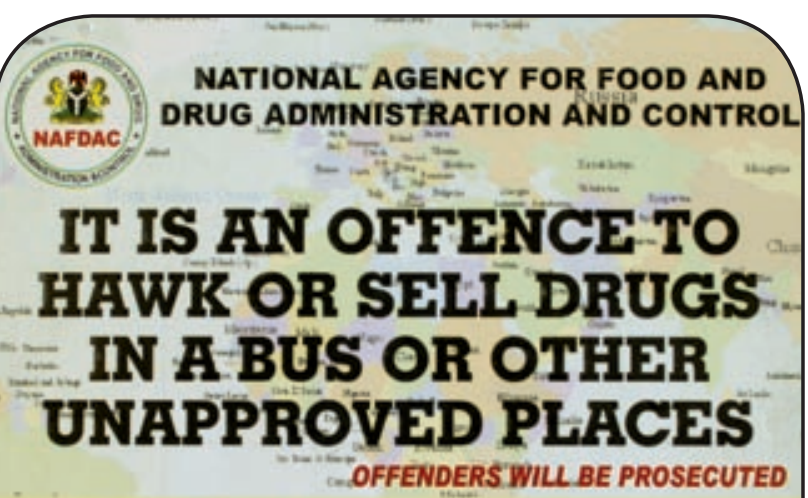

WHEN YOU SUSPECT ANY FAKE DRUG ORREGULATED PRODIICTS, CALE NAFDAC ON:

09-5240994-6, 01-2693104-5

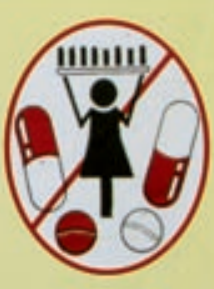

NAFDAC ...Safeguarding the Health of the Nation

Tackling the traders: Current public health campaign posters in Nigeria

and hypertension. Similar increases have been reported in the United States.

But in Europe and North America, the issue remains modest. The US Food and Drug Administration's counterfeit drug task force argued last year that extensive oversight meant the problem was still "quite rare," although it stressed that the drug supply was "increasingly vulnerable to a variety of increasingly sophisticated threats." ${ }^{5}$

Estimates issued last year by the World Health Organization's international medical products anti-counterfeiting taskforce (IMPACT), which draws together regulators, manufacturers, police, and other specialists, suggested that fakes represented less than $1 \%$ of all medicines in the industrialised world. ${ }^{67}$
However, it said that around 10\% of the global market was fake, rising to $30 \%$ in some parts of the developing world. A recent analysis of artemisinin group drugs for malaria in Kenya and Congo showed nearly a third were fake, rising to $77 \%$ for injectable forms. ${ }^{8}$

\section{Health dangers}

The public health effect is clear. Poor quality medicines cause harm by neglect because patients unwittingly take drugs that lack active ingredients. They may also be active killers, if they contain toxic elements and impurities as a result of cheap ingredients, unhygienic manufacture, or lack of rigorous cleaning between different production batches.

The situation is complicated by the fact that counterfeit drugs often contain active pharmaceutical ingredients, if only because producers are keen to both avoid detection and generate repeat business. The drugs they make may be ineffective and dangerous but difficult to spot because they use active ingredients from a similar class of medicine-swapping a patented statin for a cheaper generic form, for instance.

Other fakes contain the correct ingredients but in the wrong proportions or combinations, for reasons of cost or poor quality control. Apart from the negative consequences for individual patients' health, this can trigger broader community-wide resistance.

Counterfeiting also has an important commercial impact. It undermines the margins of legitimate drug companies, reducing the profits available for reinvestment in new drugs and for low cost, high quality generics. It cuts the tax revenues paid by these companies, 


\section{Enforcement has been modest, with scant political will or resources, because most public health scares do not take place in the developed world}

which governments can use to strengthen health systems.

Fake drugs risk damaging the reputation of drug companies, because well established brands are usurped, damaging public confidence in particular medicines or entire product ranges. Suppliers are therefore often reluctant to publicise incidents of counterfeiting of their products.

Counterfeiting has grown in part because of the high margins it offers to criminal groups, and the relatively low penalties and risks of getting caught. Enforcement has been modest, with scant political will or resources, in part because most public health scares do not take place in the developed world.

The complexity of international counterfeiting networks-which often involve production in China and India, shipment through free trade zones and countries like the UK with a good reputation, and sale through offshore distribution centres-creates particular challenges in coordinating different national police and customs services.

The internet has also helped counterfeiters, boosting the scope to market drugs anonymously by playing on peoples' desires to reduce costs and circumvent doctors' opinions by buying directly online through networks that are difficult to supervise.

\section{International response}

Rising concern has spawned initiatives such as the WHO taskforce, while both the International Narcotics Control Board and the Organisation for Economic Cooperation and Development have flagged up the problem this year. ${ }^{9} 10$ The European Parliament and the Council of Europe are considering new regulations, and some developing world regulators like Nigeria's Nafdac are seeking an international treaty. ${ }^{11}$

In 1992 the US passed legislation requiring medicines to have a "pedigree" so that they can be tracked through the supply chain, as a way to identify health problems, assist with product recalls, monitor post-launch drug safety, and gather data that could lead to the prosecution of counterfeiters. But practical problems have repeatedly pushed back guidelines and their implementation.

With legal pressure and industry appetite growing, however, a mini-industry to tackle counterfeiting has grown up. Some companies offer sophisticated scanning devices to detect pharmaceutical ingredients at the border. As part of its corporate social responsibility programme, Merck KgA produces a portable laboratory to test drugs.

Much of the debate focuses on "track and trace" technology-systems to identify genuine medicines in the supply chain. ${ }^{12}$ Although a range of sophisticated approaches have been proposed, including holograms and concealed codes printed on pills, well established methods such as radio frequency identification and two-dimensional bar codes are receiving the most attention.

There have been concerns that radio frequency identification is not always reliable, but a consensus seems to be emerging that it could be used to identify large batches throughout the distribution chain. Individual medicine packets would each be marked with a barcode that pharmacies could read using their existing equipment.

The system would require each packet to have a unique identification number that was standardised across manufacturers and consistent between countries. If the unique barcode number was ever identified more than once, had not been issued, or did not conform to the standard format, the fake would be identified.

Such a system still raises concerns, including individual patient privacy, competitive sensitivity, and the security of the database to prevent unauthorised access. But initial pilots in Belgium, a country that already has identifying numbers to help with social security reimbursement and limit fraud, have showed promise in flagging up drugs subject to recalls as much as counterfeits. ${ }^{13}$

On a global scale, practical issues with systems to stop counterfeiting remain. The biggest problem is in the developing world, where resources are limited, poor control mechanisms exist, and many medicines are supplied outside conventional, well regulated, developed world pharmacies and doctors' networks.

Technology in such locations can only be a partial solution. Advocates call for far tighter international coordination, greater funding, greater scrutiny of trans-shipment points, tougher penalties, and patient education to warn of the dangers of unregulated internet sales.

There are also broader challenges. Several drug companies have conflated counterfeit- ing with "diversion" of medicines from Canada, where they are priced more cheaply, to the United States; and the similar practice of "parallel trade" exploiting price differences within the EU. Such trading of medicines may be open to criticism on economic grounds, but where it is legal and regulated, there is scant evidence that it has led to counterfeits entering the legitimate medicines supply chain.

Despite such debates over definitions, counterfeiting is undoubtedly becoming an increasing concern, and a threat to patient health, especially in the developing world.

Andrew Jack is a pharmaceuticals correspondent at the Financial Times, London Andrew.Jack@ft.com

Competing interests: None declared.

1 Jack A. Regulator tackles fake drugs sold on internet. Financial Times 2007 Nov 22. www.ft.com/cms/s/0/ aee3d1d0-989f-11dc-8ca7-0000779fd2ac.html.

2 Medicines and Healthcare Products Regulatory Agency. Counterfeit medicines gang convicted. Press release 17 Sep 2007. www.mhra.gov.uk/home/ idcplg?ldcService=SS_GET_PAGE\&useSecondary $=$ true \&ssDocName $=$ CON2032385\&ssTargetNode Id $=389$.

3 Pfizer. Pfizer deeply concerned after discovery of another batch of counterfeit medicine. Press release 3 August 2006. www.pfizer.co.uk/template2. asp?pageid $=352$

4 European Commission Tax And Customs Union. Summary of community customs activities on counterfeit and piracy. Results at the European border, 2006. http://ec.europa.eu/taxation_customs/ resources/documents/customs/customs_controls/ counterfeit_piracy/statistics/counterf_comm _ 2006 en.pdf.

5 US Food and Drug Administration. FDA counterfeit drug task force report: 2006 update. www.fda.gov/oc/ initiatives/counterfeit/report6 06.html.

6 WHO. Counterfeit medicines. Geneva: WHO, 2006. www.who.int/mediacentre/factsheets/fs275/en/ index.html.

7 WHO. IMPACT meetings. 2007. www.who. int/medicines/services/counterfeit/impact/ impactmeetings/en/index.html.

8 Atemnkeng MA, De Cock K, Plaizier-Vercammen J. Quality control of active ingredients in artemisininderivative antimalarials within Kenya and DR Congo. Trop Med Int Health 2007;12;68-74.

9 International Narcotics Control Board. INCB warns of counterfeit medicines flooding markets. Press release, 2 March 2007. www.incb.org/pdf/e/press/2007/ annual-report-press-kit-2006-en-2.pdf.

10 Organisation for Economic Cooperation and Development. The economic impact of counterfeiting and piracy. 2007. www.oecd.org/ dataoecd/13/12/38707619.pdf.

11 Jack A. Bitter pills: the fast-growing, deadly industry in fake drugs. Financial Times 2007 May 14. http:// search.ft.com/ftArticle?queryText=akunyili\&aje=fal se $\&$ id $=070514000828 \& c t=0$.

12 WHO International Medical Products AntiCounterfeiting Taskforce. IMPACT technology subgroup meeting, 13 March 2007: meeting conclusions. www.who.int/impact/activities/IMPACTmeeting conclusions.pdf.

13 Aegate. Belgium experience. www.aegate.com/ aegate-worldwide/belgium.html. 